\title{
Drug utilization study in patients with type 2 diabetes mellitus attending diabetes clinic of a tertiary care hospital in rural Bengal
}

\author{
Sekhar Mandal ${ }^{1}$, Tamoghna Maiti ${ }^{1 *}$, Asoke Kr. Das ${ }^{1}$, Abhijit Das ${ }^{1}$, \\ Ananya Mandal ${ }^{1}$, Biswanath Sharma Sarkar ${ }^{2}$, Soumitra Mandal ${ }^{1}$
}

\begin{abstract}
${ }^{1}$ Department of Pharmacology,
${ }^{2}$ Department of Medicine,

Bankura Sammilani Medical

College, Bankura, India
\end{abstract}

Received: 14 June 2016

Accepted: 08 July 2016

\section{*Correspondence to:}

Dr. Tamoghna Maiti,

Email:dr.tamo@gmail.com

Copyright: (C) the author(s), publisher and licensee Medip Academy. This is an openaccess article distributed under the terms of the Creative Commons Attribution NonCommercial License, which permits unrestricted noncommercial use, distribution, and reproduction in any medium, provided the original work is properly cited.

\begin{abstract}
Background: Diabetes mellitus (DM) is a common and important health problem affecting the citizens of developed as well as developing nations. Not only does it require long term therapy, it is also crippling in terms of cost of management. Drug utilization studies help to determine rational drug use especially in poorer and rural populations. The objective of this study was to evaluate drug utilization pattern in type- 2 diabetes patients in a diabetic clinic of a tertiary care teaching hospital in rural Bengal.

Methods: This was a prospective observational study including 181 patients for a period of 6 months in Bankura Sammilani Medical College. Patients diagnosed as type 2 diabetes mellitus were included in the study. The demographic data, disease data and utilization of different classes of oral hypoglycaemic agents and insulin as well as other individual drugs were analysed using the World Health Organization (WHO) indicators for drug utilization studies.

Results: The study population was predominantly male $(61.33 \%)$ and nearly a third $(30.9 \%)$ belonged to the age group of 50-59 years. Co-morbid conditions were found in $74 \%$ patients, among which hypertension $(51.1 \%)$ was the most common co-morbid condition. The average number of drugs per prescription was 4.22 and the average number of antidiabetic drugs per prescription was 2.18. Metformin was the most commonly prescribed drug $(79.6 \%)$, followed by sulfonylurea class of drugs $(66.9 \%)$. Nearly $17.7 \%$ patients were on insulin preparations. Glimepiride and metformin was the most common combinations used $(45.5 \%)$. Antibiotics were included in $15.5 \%$ prescriptions and proton pump inhibitors were prescribed in $32 \%$ cases. All the medicines were prescribed as generics and injections were prescribed in $17.7 \%$ cases.

Conclusions: This study gives a picture of the pattern of drug use among diabetes patients in our set up. While metformin was the commonest drug used, glimepiride and metformin combination was the commonest combination therapy.
\end{abstract}

Keywords: Diabetes mellitus, Drug utilization, Metformin

\section{INTRODUCTION}

The main aim of drug utilization research is to assess whether the drug treatment is rational or not. To reach this goal, methods of auditing drug therapy towards rationality are necessary. ${ }^{1}$ History has taught us that successful research in drug utilization requires multidisciplinary collaboration between clinicians, clinical pharmacologists, pharmacists and epidemiologists. ${ }^{1}$ The study of drug utilization is an evolving field. The use of large computerized databases that allow the linkage of dug utilization data to diagnosis is contributing to expansion of this area. ${ }^{2}$

Diabetes is a group of metabolic diseases characterized by hyperglycaemia resulting from defects in insulin secretion, insulin action, or both. The chronic hyperglycaemia of diabetes is associated with long-term damage, dysfunction and failure of various organs, especially the eyes, kidneys, nerves, heart and blood 
vessels. ${ }^{3}$ According to International diabetes federation (IDF), 65.1 million of adults in India suffered from diabetes in the year $2013 .^{4}$ It has been predicted that the prevalence of diabetes in the adult population in India will be $6 \%$ by the year $2025 .^{5}$ Modern principles of management of diabetes focus on disease prevention, screening high risk individuals and aggressive treatment of individuals in the pre-diabetic state. ${ }^{6-8}$

As per American diabetes association (ADA) guidelines 2015 , the treatment protocols for type 2 diabetes mellitus would be Metformin, if not contraindicated and if tolerated, is the preferred initial pharmacological agent for type 2 Diabetes. If the A1c target is not achieved after approximately 3 months, consider a combination of metformin and one of these six treatment options: sulfonylureas, thiazolidinedione's, DPP-4 inhibitors, SGLT2 inhibitors, GLP-1 receptor agonists or basal insulin. ${ }^{9}$

In this pre-set we planned our study in a tertiary care teaching hospital where there was a separate clinic for diabetes patients but lack of adequate data on the drug utilization pattern of antidiabetic medicines. We tried to mend this informational gap.

\section{METHODS}

The objective of this study was to evaluate drug utilization in a diabetic clinic of a tertiary hospital. And to assess the number of antidiabetic drugs used per prescription. And to assess if the prescriptions are as per standard guidelines or not.

Study conducted was diabetes clinic of Bankura Sammilani Medical College, Bankura.

\section{Inclusion criteria}

All type 2 diabetes mellitus cases between the age group of 30 to 70 years, attending diabetes clinic of BSMC.

\section{Exclusion criteria}

- Type 1 DM

- Young diabetics below 30 years of age

- Gestational DM.

\section{Methods of data collection}

The study was conducted after obtaining ethical clearance from the institutional ethics committee of Bankura Sammilani Medical College, Bankura. Informed consent was taken from all study subjects fulfilling the criteria. Then data were collected from the OPD prescriptions and a brief interview of the individuals, which was conducted with the help of the pre-designed case report form. Within the study period, 6 months April 2014- September 2014 was allotted for data collection from the study subjects.
The design of this study was institution based longitudinal prospective observational unicentric study

A total of 181 prescriptions were randomly evaluated for prescribing pattern in type 2 diabetes mellitus patients using WHO drug indicators like drug class, dosage form, fixed dose combinations (FDCs), generic and branded drugs and drugs from NLEM 2011. DDD/1000 inhabitants/day was also calculated.

\section{DDD/1000/day}

The DDD/1000/day was calculated as follows,

DDD/1000inhabitant/day $=$

Total no. of dosage form units prescribed $\times$ strength of each dosage unit

DDD $\times$ Duration of study $\times$ total sample size

\section{Statistical analysis}

IBM SPSS version 22 (statistical package for social sciences Inc., USA) software package was used for data stratification and analysis. Descriptive statistics were used. Paired t-test was used wherever required.

\section{RESULTS}

\section{Demographic details}

Total 181 patients were included in this study.

Among them $111(61.33 \%)$ patients were male and 70 $(38.67 \%)$ were female. Male: female ratio was 1.58:1 (approx.).

Majority of the patients $(30.9 \%)$ were in the age group of 50 to 59 (Figure 1). The mean age of the study population was found to be 52.50 years with a standard deviation of 9.949 years (Table 1$)$.

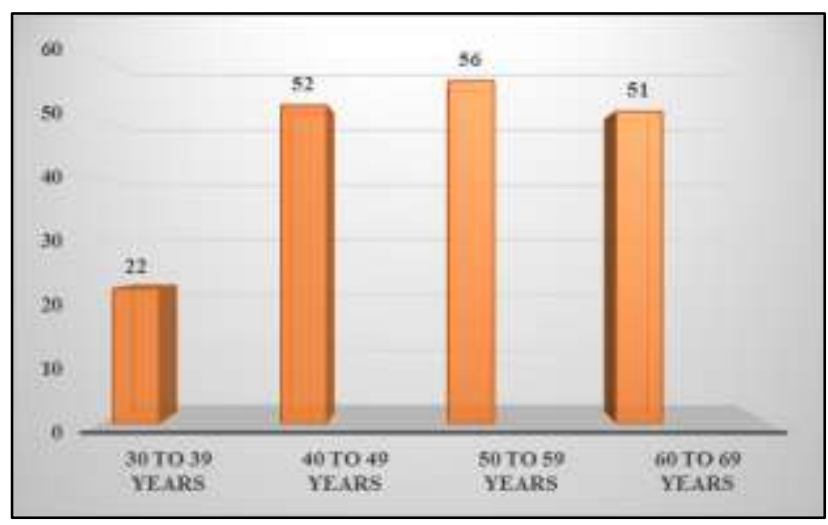

Figure 1: Age group wise distribution.

Almost half of the patients were found to be obese and 29.3\% were overweight (Figure 2). As per Asia Pacific perspective for Asians (WHO IOTF 2003). ${ }^{10}$ 
Table 1: Demographic variables of study subjects.

\begin{tabular}{|lllll|}
\hline Parameters & $\begin{array}{l}\text { Mean } \\
\text { value }\end{array}$ & $\begin{array}{l}\text { Standard } \\
\text { deviation }\end{array}$ & Maximum & Minimum \\
\hline $\begin{array}{l}\text { Age in } \\
\text { years }\end{array}$ & 52.50 & 9.949 & 69 & 31 \\
\hline $\begin{array}{l}\text { Height } \\
(\mathrm{cm})\end{array}$ & 162.39 & 5.847 & 185 & 150 \\
\hline $\begin{array}{l}\text { Weight } \\
(\mathrm{kg})\end{array}$ & 65.10 & 8.875 & 90 & 42 \\
\hline $\begin{array}{l}\text { BMI } \\
\left(\mathrm{kg} / \mathrm{m}^{2}\right)\end{array}$ & 24.62 & 2.59 & 30.49 & 17.48 \\
\hline $\begin{array}{l}\text { Monthly } \\
\text { family } \\
\text { income } \\
\text { (INR) }\end{array}$ & 13230 & 7188 & 42000 & 1500 \\
\hline
\end{tabular}

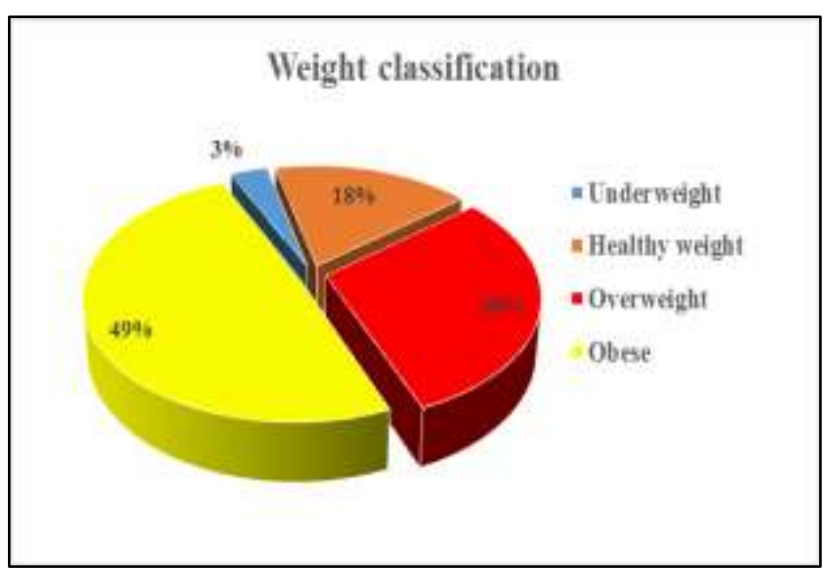

Figure 2: Distribution of study samples as per their BMI.

\section{Significant comorbidities}

Total 134 patients $(74.0 \%)$ were suffering from associated comorbidities. Hypertension $(50.8 \%)$ being the commonest comorbidity followed by dyslipidemia $(24.3 \%)$, neuropathy $(13.8 \%)$ coronary vascular diseases (10.5\%) and nephropathy (3.9\%) (Figure 3).

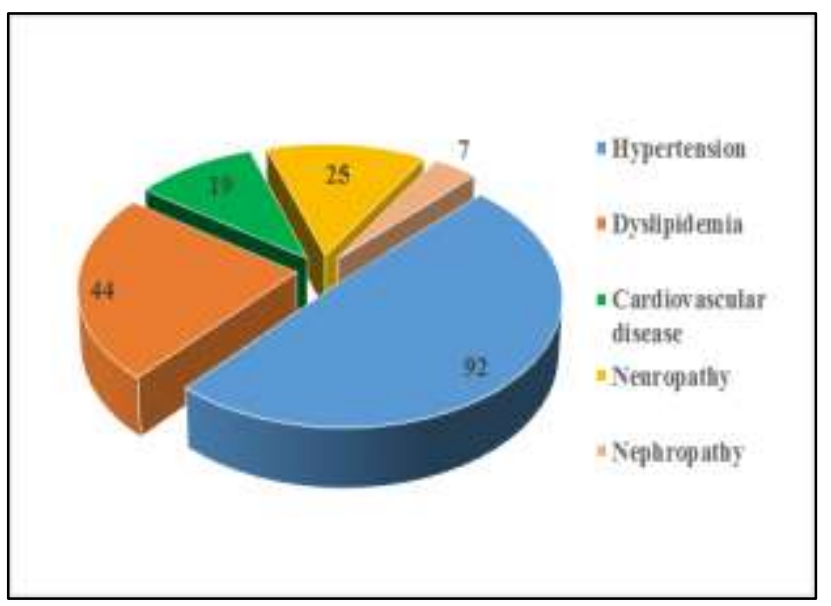

Figure 3: Chart of significant comorbidities.

\section{Pattern of drug use}

\section{Antidiabetic drugs prescribed}

In the overall utilization pattern, metformin (79.6\%) was the most frequently prescribed oral hypoglycaemic agent followed by sulfonylureas $(66.9 \%)$. Thiazolidinedione's (pioglitazone) were prescribed in $20.4 \%$ cases. DPP4 inhibitors and $\alpha$ glucosidase inhibitors were prescribed $16.6 \%$ cases only. Thus amongst the antidiabetic agents used the maximum percentage was of metformin, followed by sulfonylureas, insulin and thiazolidinedione's. $\alpha$-Glucosidase inhibitors and DPP4 inhibitors were used to a much lesser extent (Figure 4).

Metformin was prescribed in different doses ranging from $500 \mathrm{mg}$ to $2000 \mathrm{mg}$ daily. Most commonly prescribed dose was $1000 \mathrm{mg}$ daily (55.6\%). Daily dose of $500 \mathrm{mg}$, $1.5 \mathrm{gm}$ and $2 \mathrm{gm}$ were prescribed to 37,15 and 10 patients respectively out of 144 receivers (Figure 5).

Among sulfonylureas the commonest drug used was glimepiride $(78.51 \%)$ and most frequently prescribed daily dose was $2 \mathrm{mg}$ (Figure 6).

Insulin was prescribed in $32(17.7 \%)$ patients. Among them 7 patients got regular insulin and the rest of them were given premixed human insulin.

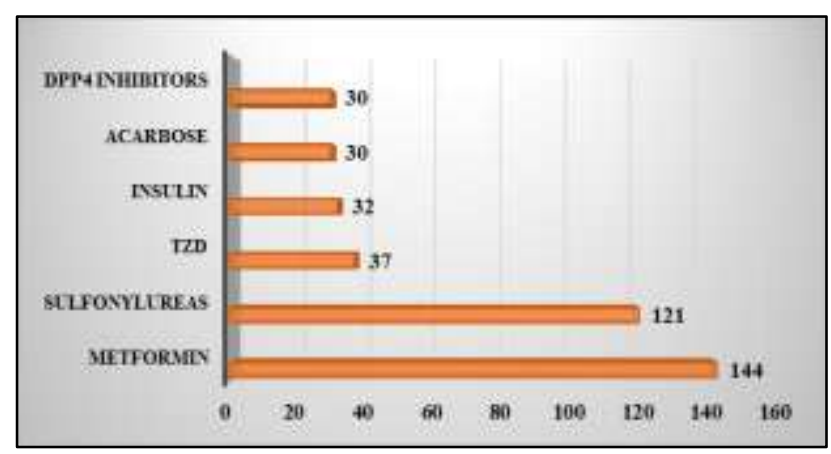

Figure 4: Pattern of antidiabetic drugs prescription.

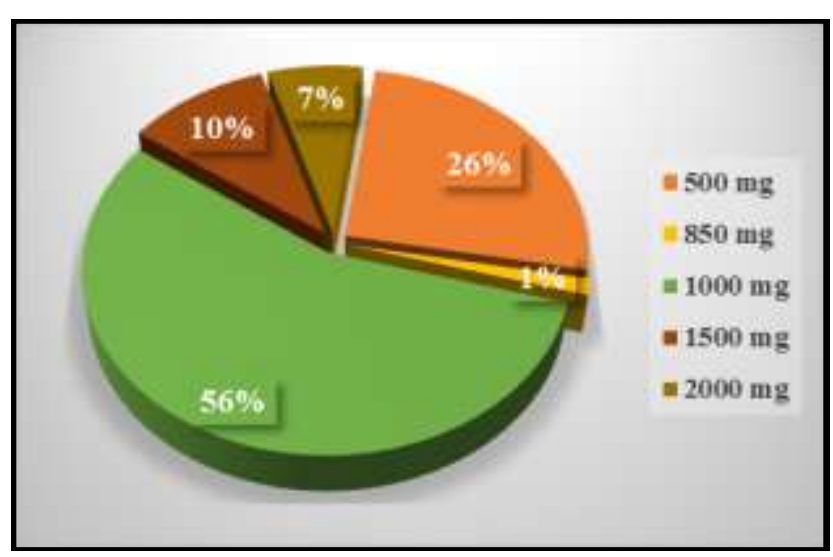

Figure 5: percentage of use of metformin in different doses $(n=144)$. 


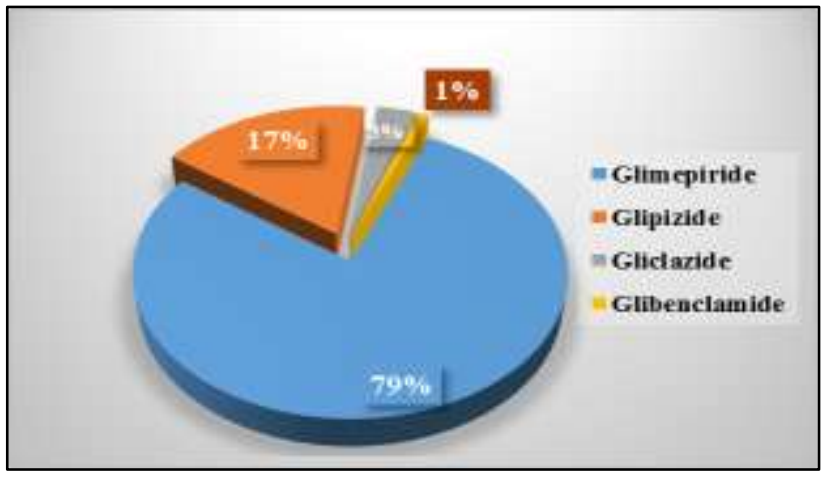

Figure 6: Percentage of use of different sulfonylureas. $(n=121)$.

\section{Distribution of antidiabetic therapy}

Most of the patients received more than 1 antidiabetic drug. Monotherapy was given to 28 patients (15.5\%) only. More than a half (55.87) of the study samples received 2 antidiabetic drugs and almost a quarter $(24.3 \%)$ of all the subjects received 3 drug therapy. Very few (4.4\%) have got 4 drug therapies (Figure 7 ).

Table 2: Prescription pattern of antidiabetic drugs based on combination therapy.

\begin{tabular}{|lll|}
\hline $\begin{array}{l}\text { Two-drug combination } \\
\text { therapy }(\mathbf{n = 1 0 1})\end{array}$ & Frequency & Percentage \\
\hline Metformin+glimepiride & 46 & 45.54 \\
\hline Metformin+insulin & 6 & 5.94 \\
\hline Metformin+glipizide & 12 & 11.88 \\
\hline Metformin+voglibose & 10 & 9.9 \\
\hline Metformin+pioglitazone & 5 & 4.95 \\
\hline Three-drug combination therapy $(\mathbf{n}=\mathbf{4 4})$ \\
\hline $\begin{array}{l}\text { Metformin+glimepiride+ } \\
\text { pioglitazone }\end{array}$ & 16 & 36.36 \\
\hline $\begin{array}{l}\text { Metformin+glimepiride+ } \\
\text { insulin }\end{array}$ & 4 & 9.09 \\
\hline $\begin{array}{l}\text { Metformin+glimepiride+ } \\
\text { voglibose }\end{array}$ & 4 & 9.09 \\
\hline $\begin{array}{l}\text { Metformin+glipizide+pio } \\
\text { glitazone }\end{array}$ & 3 & 6.81 \\
\hline
\end{tabular}

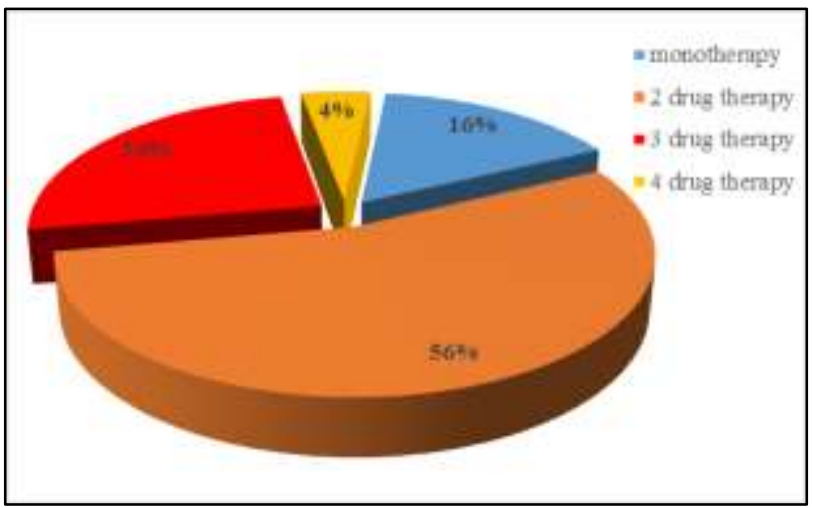

Figure 7: Distribution of antidiabetic therapy $(n=181)$.
The most commonly prescribed two drug combination was metformin and glimepiride (45.54\%). In three drug combinations, metformin glimepiride and pioglitazone were most frequently prescribed $(36.36 \%)$ (Table 2$)$.

\section{Other drugs}

Antihypertensive drugs were prescribed very commonly as hypertension was the most frequent associated comorbidity in the study samples. Among them angiotensin converting enzyme inhibitors/ angiotensin receptor blockers were given in 63 patients $(34.80 \%)$ (Figure 8). Calcium channel blockers were given in 29 $(16 \%)$ cases. Diuretics were prescribed in 19 cases $(10.49 \%)$. Beta blockers were less frequently used, being only in 12 cases $(6.62 \%)$.

Anticoagulants were prescribed to 33 patients (18.23\%). Among them aspirin $75 \mathrm{mg}$ was given most commonly (31 cases) and clopidogrel $75 \mathrm{mg}$ was given only in 2 cases.

HMG-Co A reductase inhibitors were given in 95 patients $(52.48 \%)$. Atorvastatin was given to 75 patients and rosuvastatin in 20 patients. For diabetic neuropathy, patients were prescribed cyclic GABA analogues. They were given to 25 patients $(13.82 \%)$. Nitrates were given in 9 cases. Proton pump inhibitors were prescribed in 58 cases $(32.04 \%)$. Among them pantoprazole was commonest (38 cases).

Antimicrobials were prescribed in 28 encounters only $(15.47 \%)$. Antibiotics were given to patients who had some infections e.g. urinary tract infection, respiratory tract infection, etc. Azithromycin (21.42\%) and levofloxacin $(21.42 \%)$ was used most commonly among antibiotics (Figure 8).

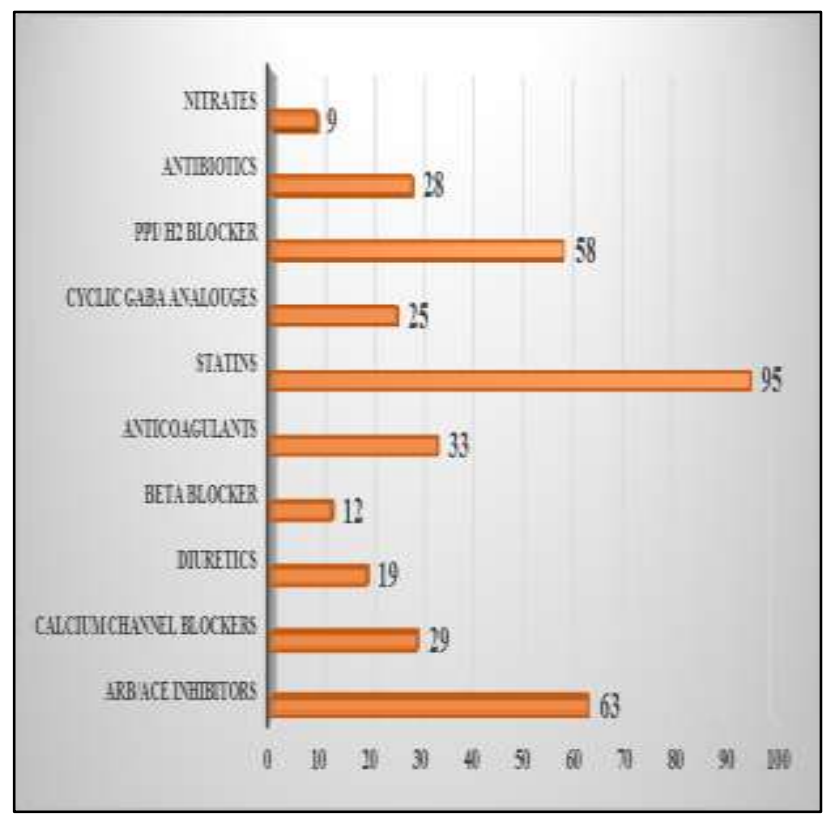

Figure 8: Pattern of other drugs prescription. 


\section{Core drug use indicators}

Key prescribing indicators

- Average number of drugs per prescription (encounter) - 4.22

- Average number of antidiabetic drugs per prescription (encounter) - 2.18

- Percentage of drugs prescribed by generic name $78.86 \%$

- Percentage of encounters with an antibiotic prescribed - $15.47 \%$

- Percentage of encounters with an injection prescribed $-17.7 \%$

- $\quad$ Percentage of drugs prescribed from essential drugs list (NLEM 2011) - 42.31\%

- Average drug cost per encounter - 13.50 INR.

Patient care indicators

- Average consulting time - 8.48 minutes

- Average dispensing time - 1.26 minutes

- Percentage of drugs actually dispensed - $85 \%$

- Patient's knowledge of correct dosage - $69.06 \%$.

\section{Facility indicators}

- Availability of copy of essential drug list or formulary - Yes

- Availability of key drugs - 90\%.

While comparing the average daily dose of the drug with WHO/ATC defined daily dose, it was found that average daily doses of most of the antidiabetic drugs were less than their DDD. Gliclazide had higher average daily dose while that of linagliptin and saxagliptin was same as their DDD (Table 3).

Table 3: Difference between averages prescribed doses and defined daily doses of drugs for the treatment of type 2 diabetes mellitus.

\begin{tabular}{|lll|}
\hline Drugs & Average dose & DDD \\
\hline Metformin (A10BA02 & $990.97 \mathrm{mg} /$ day & $2000 \mathrm{mg}$ \\
\hline Insulin (A10AC01) & $32.09 \mathrm{IU} /$ day & $40 \mathrm{IU}$ \\
\hline Glimepiride (A10BB12) & $1.50 \mathrm{mg} /$ day & $2 \mathrm{mg} /$ day \\
\hline Glipizide (A10BB07) & $5.23 \mathrm{mg} /$ day & $10 \mathrm{mg} /$ day \\
\hline Gliclazide (A10BB09) & $70 \mathrm{mg} /$ day & $60 \mathrm{mg} /$ day \\
\hline Glibenclamide (A10BB01) & $5 \mathrm{mg} /$ day & $7 \mathrm{mg} /$ day \\
\hline Pioglitazone (A10BG03) & $14 \mathrm{mg} /$ day & $30 \mathrm{mg} /$ day \\
\hline Acarbose (A10BF01) & $37.5 \mathrm{mg} /$ day & $300 \mathrm{mg} /$ day \\
\hline Voglibose (A10BF03) & $0.29 \mathrm{mg} /$ day & $\mathrm{NA}$ \\
\hline Vildagliptin (A10BH02) & $50 \mathrm{mg} /$ day & $100 \mathrm{mg} /$ day \\
\hline Linagliptin (A10BH05) & $5 \mathrm{mg} /$ day & $5 \mathrm{mg} /$ day \\
\hline Sitagliptin (A10BH01) & $50 \mathrm{mg} /$ day & $100 \mathrm{mg} /$ day \\
\hline Saxagliptin (A10BH03) & $5 \mathrm{mg} /$ day & $5 \mathrm{mg} /$ day \\
\hline
\end{tabular}

\section{Calculation of DDD/100 inhabitants/day}

DDD/1000 inhabitants/day was calculated for antidiabetic drugs. It was not possible for voglibose as the DDD was not mentioned for this drug by WHO/ATC. It was found to be highest for glimepiride followed by metformin (Table 4).

Table 4: DDD/100 inhabitants/day of the antidiabetic drugs.

\begin{tabular}{|lll|}
\hline Antidiabetic drug & $\begin{array}{l}\text { DDD/1000 } \\
\text { inhabitants/day }\end{array}$ & Percentage \\
\hline Glimepiride & 502 & 38.14 \\
\hline Metformin & 394 & 29.93 \\
\hline Insulin & 142 & 10.79 \\
\hline Pioglitazone & 95.3 & 7.24 \\
\hline Glipizide & 60.77 & 4.62 \\
\hline Sitagliptin & 38.67 & 2.94 \\
\hline Vildagliptin & 35.91 & 2.73 \\
\hline Gliclazide & 25.78 & 1.96 \\
\hline Linagliptin & 11.05 & 0.84 \\
\hline Saxagliptin & 5.52 & 0.42 \\
\hline Glibenclamide & 3.94 & 0.30 \\
\hline Acarbose & 1.38 & 0.11 \\
\hline
\end{tabular}

\section{Calculation of DU $90 \%$}

Consumption of all the antidiabetic drugs were calculated in terms of their DDDs and it was found that DU90\% of the drugs comprised:

- Glimepiride

- Metformin

- Insulin

- Pioglitazone

- Glipizide.

(Ranked as per their consumptions during the study period in volumes of DDDs).

\section{Index of adherence}

As per ADA guidelines, metformin is preferred drug for the treatment of type 2 diabetes mellitus if there is no contraindication to use metformin. In our study metformin was prescribed to $79.6 \%$ patients. In contrast, glimepiride was found to be more utilized when we calculated the consumption in terms of their DDDs. There is underutilization of metformin in terms of DDD.

\section{Adverse drug reactions}

Adverse drug reactions were noted and recorded. Causality was assessed using WHO-UMC scale and severity was assessed using Hartwig-Siegel criteria. The adverse drug reactions that we had found during the study period were; 
- Metformin induced GI upset in 5 patients. Glimepiride induced hypoglycemia in 3 patients, and rash in 2 patients. Voglibose induced flatulent dyspepsia in 5 patients

- Amlodipine induced pedal edema in 1 patient. ACE inhibitors induced dry cough in 3 patients. Beta blockers induced bradycardia in 2 patients

- Pregabalin induced dizziness in 2 patients.

No serious adverse event occurred during the study period.

\section{DISCUSSION}

In this study, the prevalence of diabetes was found to be more common among male population with a male: female ratio of 1.58:1. This is comparable with a similar previous study done by Rani $\mathrm{J}$ et al where they found the ratio to be $1.4: 1 .^{11}$ Male preponderance was seen in other studies done in India, USA and other countries. ${ }^{12-15}$

In our study it was found that prevalence of type 2 diabetes was high in the middle aged persons, i.e. 40 to 60 years of age. The mean age of the study population was found to be 52.5 years. This was similar with few recent studies done in India and outside but is lower when compared to some other previous studies where the mean age was found to be around 60 years. ${ }^{16-21}$ It may be attributed to the fact that type $2 \mathrm{DM}$ is now-a-days affecting younger population compared to previous days.

Almost half of the patients were found to be obese and $29.3 \%$ were overweight. It clearly indicates the prevalence of type 2 diabetes in obese and overweight patients. The mean BMI of the study population was 24.62 .

Most of the patients (74\%) were suffering from other comorbid conditions like hypertension (50.8\% patients), dyslipidemia (24.3\% patients), etc. the comorbidities played a major role on the disease burden and also it increases cost of therapy and deteriorates the quality of life.

Amongst antidiabetic medications, metformin was the most commonly prescribed drug which was given in 144 $(79.6 \%)$ patients followed by sulphonylureas in 121 $(66.9 \%)$ and pioglitazone in $37(20.4 \%)$ patients. Similar utilization pattern was observed in another study by Vengurlekar S et al and Dhanaraja et al Most of the patients required two or more drugs to achieve glycemic control. $^{22,23}$ The most possible reason for this is that type $2 \mathrm{DM}$ is a chronic disease with a progressive deterioration in glycemic control due to the continuing loss of $\beta$-cell function and hence forth. Monotherapy for type 2 diabetes may therefore not be sufficient to maintain glycemic control over time. ${ }^{24}$

The most commonly prescribed two drug combination was metformin and glimepiride (45.54\%). Similar results were obtained in the studies done by Dutta $\mathrm{S}$ et al, Vengurlekar S et al and Patel B et al. ${ }^{16,22,25}$

In this study we have found that insulin was prescribed in 32 patients i.e. $17.7 \%$ of the total study sample. It is quite high when compared to a study done in Northern India by Dutta $S$ et al, where the frequency of Insulin prescription was $1.80 \%{ }^{16}$ This pattern is somehow similar to the pattern of Insulin use in a tertiary care hospital of western India, as highlighted by Dave DJ et al. ${ }^{26}$

The most commonly co-prescribed medications along with antidiabetic drugs were antihypertensive drugs which is similar with a study from India and Nigeria. ${ }^{16,27}$ The high antihypertensive prescriptions reflect the high rate of co-morbidity of hypertension and diabetes.

The total number of drugs prescribed per prescription was 4.22, which was similar when compared to a study done by Dutta $S$ et al, where average number of drugs per prescription was 3.98 , but is less if compared to the studies by Kumar MA et al and Patel B et al, where 6.51 and 7.58 drugs were prescribed per prescription respectively. ${ }^{16,28,25}$ Drugs were prescribed by their respective generic names in $78.86 \%$ times. This was higher compared to similar studies. This indicated the increase in the trend of prescribing generic drugs. A low percentage of injection utilization from this study was observed because we had taken only type- 2 diabetes patients attending diabetic clinic which is an outpatient department. The only prescribed injection was insulin. This finding was in accordance with a study done in western part of India. ${ }^{25}$

DDD/100 inhabitants/day was calculated for the antidiabetic drugs prescribed and it was found to be highest for glimepiride followed by metformin. DU $90 \%$ comprised of glimepiride, metformin, insulin, pioglitazone and glipizide.

Cost of prescription is important in chronic diseases like diabetes. In this study, average prescription cost per day was INR 13.50, which was less than the other studies by Kannan et al and Dutta S. ${ }^{16,29}$ The reduced cost may be due to prescribing medicines by generic names and less number of medications per prescription.

The other area which needed attention was patient education and knowledge. $30.94 \%$ of patients lacked adequate knowledge of dosage schedule, possibly due to communication error. Pharmacists can be urged to spend more time with dispensing since at the moment only 1.26 minutes were spent for each encounter. This simple measure would probably help patients understand their dosage schedule better.

The overall prescribing practice was found to be rational and good compared to other parts of India, but there are many scopes to improve. 
The limitations of this study was all studies, ours too had some limitations. Some of the notable limitations of our study included -

- Sample size of our study was small

- The study was done in a very short period. Further long term studies can be done to attain more reproducible data

- The study was based on OPD only. It can be done in inpatients department in future to know utilization of antidiabetic drugs in admitted patients

- As it is a unicentric study, utilization pattern from others centers treating diabetes could not be obtained.

\section{CONCLUSION}

This study showed that type $2 \mathrm{DM}$ is more prevalent in men than in women, obese and overweight patients are at higher risk. Type $2 \mathrm{DM}$ is not confined to urban population or the upper class of the society. The study had shown metformin as the most commonly prescribed oral antidiabetic drug both in monotherapy or combination therapy, but still there was underutilization of this drug. Newer antidiabetic drugs were prescribed less frequently. Adherence of the prescriptions to the recent ADA guideline was found to be good, but it could have been better with a higher prescription of metformin. The prescribing trend also appears to be moving towards combination therapy particularly two drug therapy. Patient care indicators were found to be good as the average patient consulting time was adequate and most of the drugs were dispensed. But many patients did not have adequate knowledge about correct dosage. From our study we can conclude that most of the prescriptions were rational, but further improvement in prescribing practices is necessary.

\section{Funding: No funding sources}

Conflict of interest: None declared

Ethical approval: The study was approved by the Institutional Ethics Committee

\section{REFERENCES}

1. Introduction to Drug Utilization Research. Oslo, Norway. WHO; 2003:1-73.

2. Sachdeva PD, Patel BG. Drug utilization studiesscope and future perspectives. International Journal on Pharmaceutical and Biological Research. 2010;1:11-7.

3. American Diabetes Association. Diagnosis and classification of diabetes mellitus. Diabetes Care. 2012;35(Suppl 1):64-71.

4. IDF Diabetes Atlas. $6^{\text {th }}$ ed. International Diabetes Federation, 2013. Available at http://www.idf.org. Accessed on July 2015.

5. King H, Aubert RE, Herman WH. Global burden of diabetes, 1995. 2025: prevalence, numerical estimates, and projections. Diabetes Care. 1998;21:1414-31.
6. Unger J. Current strategies for evaluating, monitoring, and treating type 2 diabetes mellitus. Am J Med. 2008;121(Suppl 6):S3-8.

7. Krentz AJ, Bailey CJ. New drugs for type 2 diabetes: What is their place in therapy? Drugs. 2008;68:213162.

8. El-Kaissi S, Sherbeeni S. Pharmacological management of type 2 diabetes mellitus: an update. Curr Diabetes Rev. 2011;7:392-405.

9. American Diabetes Association. Standards of medical care in Diabetes-2015. Diabetes care. 2015;38(Suppl 1):S41-8.

10. Who Asia Pacific perspective for Asians (WHO IOTF 2003). Appropriate body-mass index for Asian populations and its implications for policy and intervention strategies. Lancet. 2004;363:157-63.

11. Rani J, Reddy S. Prescribing pattern of antidiabetic drugs in urban population of Hyderabad. Natl $\mathbf{J}$ Physiol Pharm Pharmacol. 2015;5:5-9.

12. Sudha V, Shukla P, Patidar P. Prescribing pattern of antidiabetic drugs in Indore city hospital Indian. Journal of Pharmaceutical Sciences. 2008;70:637-40.

13. Boccuzzi SJ, Wogen J, Fox J. Utilization of oral hypoglycemic agents in a drug-insured U.S. Population. Diabetes Care. 2004;24:1411-5.

14. Johnson JA, Pohar SL, Secnik K. Utilization of diabetes medication and cost of testing supplies in Saskatchewan, 2001. BMC Health Serv Res. 2006;6:159.

15. Yurgin N, Secnik K, Lage MJ. Antidiabetic prescriptions and glycemic control in German patients with type 2 diabetes mellitus: a retrospective database study. Clin Ther. 2007;29:316-25.

16. Dutta S, Beg MA, Anjoom M, Varma A, Bawa S. Study of prescribing pattern in diabetes mellitus patients in a tertiary care teaching hospital at Dehradun, Uttarakhand. Int J Med Sci Public Health. 2014;3:1351-4.

17. Adibe MO, Aguwa CN, Ukwe CV, Okonta JM, Udeogaranya PO. Outpatient utilization of antidiabetic drugs in the South Eastern Nigeria. Int J Drug Dev and Res. 2009;1:27-36.

18. John LJ, Arifulla M, Sreedharan J, Muttappallymyalil J, Das R, John J et al. Age And Gender-Based Utilization Pattern of Antidiabetic Drugs In Ajman, UAE. Malaysian J of Pharm Sci. 2012;10:79-85.

19. Abdi SAH, Churi S, Kumar YSR. Study of drug utilization pattern of antihyperglycemic agents in a South Indian tertiary care teaching hospital. Indian $\mathbf{J}$ Pharmacol. 2012; 44:210-4.

20. Guercil B, Drouin P. Self-monitoring of blood glucose significantly improves metabolic control in patients with type 2 diabetes mellitus: the AutoSurveillance Intervention Active (ASIA) study diabetes Metab 2003; 29:587-94.

21. Mastura I, Chew BH, Lee PY, Cheong AT, Sazlina $\mathrm{SG}$, Jamaiyah $\mathrm{H}$, et al. Control and Treatment Profiles of 70,889 Adult Type 2 Diabetes Mellitus Patients in Malaysia - A Cross Sectional Survey in 2009. International Journal of Collaborative Research 
on Internal Medicine \& Public Health 2011; 3:98113.

22. Vengurlekar S, Shukla P, Patidar P, Bafna R, Jain S. Prescribing pattern of antidiabetic drugs in Indore city hospital. Indian J Pharm Sci 2008; 70:637-40.

23. Dhanraja E, Raval AD, Yadav R, Bhansali A, Tiwari P. Prescribing pattern of antidiabetic drugs and achievement of glycemic control in T2DM patients in tertiary care hospital in North India. International Journal of Diabetes in Developing Countries 2013:33:140-6.

24. Barnett AH. Redefining the role of thiazolidinediones in the management of type 2 diabetes. Vasc Health Risk Manag. 2009;5(1):141-51.

25. Patel B, Oza B, Patel KP, Malhotra SD, Patel VJ. Pattern of antidiabetic drugs use in type-2 diabetic patients in a medicine outpatient clinic of a tertiary care teaching hospital. Int $\mathrm{J}$ Basic Clin Pharmacol. 2013;2:485-91.
26. Dave DJ, Dikshit RK, Gandhi AM. Utilization of some newer oral antidiabetic agents in a tertiary care hospital. Natl J Physiol Pharm Pharmacol. 2012;2:146-51.

27. Jimoh AO, Sabir AA, Chika A, Sani Z. Pattern of Antidiabetic drugs use in a diabetic outpatient clinic of a tertiary health institution in Sokoto, Northwestern Nigeria. Journal of Medical Sciences. 2011;11:241-5.

28. Kumar MA, Nizar A, Shailaja K, Jayasutha J, Ramasamy C. A study on prescribing pattern and potential drug-drug interactions in type 2 diabetes mellitus in a tertiary care teaching hospital. Der Pharmacia Lettre. 2011:3:13-9.

29. Arshad K, Kumar S. A study on drug utilization of oral hypoglycemic agents in type-2 diabetic patients. Asian J Pharm Clin Res. 2011;4:60-4.

Cite this article as: Mandal S, Maiti T, Das AK, Das A, Mandal A, Sarkar BS, et al. Drug utilization study in patients with type 2 diabetes mellitus diabetes clinic of a tertiary care hospital in rural Bengal. Int J Basic Clin Pharmacol 2016;5:1647-54. 